\title{
AFLP Fingerprinting for Identification of Infra-Species Groups of Rhizoctonia solani and Waitea circinata
}

\author{
Bimal S. Amaradasa1*, Dilip Lakshman² and Keenan Amundsen ${ }^{3}$
}

${ }^{1}$ Department of Plant Pathology, University of Nebraska-Lincoln, Lincoln, NE 68583, USA

${ }^{2}$ Floral and Nursery Plants Research Unit and the Sustainable Agricultural Systems Lab, Beltsville Agricultural Research Center-West, Beltsville, MD 20705, USA

${ }^{3}$ Department of Agronomy and Horticulture, University of Nebraska-Lincoln, Lincoln, NE 68583 USA

\begin{abstract}
Patch diseases caused by Thanatephorus cucumeris (Frank) Donk and Waitea circinata Warcup and Talbot varieties (anamorphs: Rhizoctonia species) pose a serious threat to successful maintenance of several important turfgrass species. Reliance on field symptoms to identify Rhizoctonia causal agents can be difficult and misleading. Different Rhizoctonia species and Anastomosis Groups (AGs) vary in sensitivity to commonly applied fungicides and they also have different temperature ranges conducive for causing disease. Thus correct identification of the causal pathogen is important to predict disease progression and make future disease management decisions. Grouping Rhizoctonia species by anastomosis reactions is difficult and time consuming. Identification of Rhizoctonia isolates by sequencing Internal Transcribed Spacer (ITS) region can be cost prohibitive. Some Rhizoctonia isolates are difficult to sequence due to polymorphism of the ITS region. Amplified Fragment Length Polymorphism (AFLP) is a reliable and cost effective fingerprinting method for investigating genetic diversity of many organisms. No detailed analyses have been done to determine the suitability of AFLP for inferring infra-species level of Rhizoctonia isolates. The objective of the present study was to develop AFLP fingerprinting to identify infra-species level of unknown $R$. solani Kühn and $W$. circinata isolates. Seventy-nine previously characterized $R$. solani $(n=55)$ and $W$. circinata $(n=24)$ isolates were analyzed with AFLP markers generated by four primer pairs. Unweighted Pair Group Method with Arithmetic Mean (UPGMA) correctly grouped $R$. solani and W. circinata isolates according to their AG, AG subgroup or W. circinata variety. Principle component analysis (PCA) corroborated UPGMA clusters. To our knowledge this is the first time AFLP analysis has been tested as a method to decipher the AG, AG subgroup or W.circinata variety across a wide range of Rhizoctonia isolates.
\end{abstract}

Keywords: AFLP; Rhizoctonia solani; Waitea circinata; anastomosis groups; turfgrasses

\section{Introduction}

Patch diseases caused by multiple Rhizoctonia species pose a serious threat to growth and maintenance of several important turfgrass species in the southern and transition zones of the USA $[1,2]$. The transition zone refers to the central part of the country where climatic conditions are not favorable for either cool-season or warmseason turfgrasses. However, both turfgrass types are routinely grown and managed in this region. The form-genus Rhizoctonia includes uninucleate, binucleate, and multinucleate species, and of these, multinucleate Thanatephorus cucumeris (Frank) Donk (=R. solani Kühn) and Waitea circinata Warcup and Talbot varieties agrostis, zeae, oryzae, circinata, and prodigus; and binucleate Ceratobasidium cereale Murray and Burpee $(=R$. cerealis Van der Hoeven, AG-D) have been reported from diseased turf lawns and golf greens [1-4]. Rhizoctonia solani is a genetically diverse species consisting of many Anastomosis Groups (AGs) [5,6]. Six AGs have been reported to cause blight in turfgrass with AG 1(-IA and -IB), AG 2 (-2IIIB and -2LP), and AG 4 being more common on infected turfgrasses than other AGs $[7,8]$.

Reliance on field symptoms to identify Rhizoctonia causal agents can be difficult and misleading. In general, Rhizoctonia affected turfgrasses show circular areas of blighted brown colour leaves. Microscopically, all Rhizoctonia species look more or less similar, i.e. nonsporulating mycelia with 90 degree branches having dolipore septa [8]. However, R. solani isolates can be distinguished from W. circinata varieties by colony morphology on Potato Dextrose Agar (PDA). Rhizoctonia solani produces brown to dark brown sclerotia on PDA whereas sclerotia of $W$. circinata are orange to salmon in the formative stages and darkens to brown as cultures age $[1,2,8]$. Also, sclerotia of $W$. circinata are frequently submerged in the media unlike $R$. solani which are formed on the agar surface. Although, colony morphology on PDA can differentiate $R$. solani from $W$. circinata, colony features are not reliable to distinguish AGs within these species. It is common to isolate multiple Rhizoctonia species and AGs from infected turfgrasses. Different Rhizoctonia species and AGs vary in sensitivity to commonly applied fungicides [9-12] and they also have different temperature ranges conducive for causing disease [8]. Therefore, correct identification of the causal pathogen and its AG is important to predict the disease progression and make future disease management decisions. For plant breeders, knowledge of the main causal pathogens at different locations is important for selecting appropriate turfgrass germplasm with resistance to Rhizoctonia blight.

The classical method of grouping isolates of Rhizoctonia is based on anastomosis with tester strains. However this method is sometimes difficult to interpret and may take excessive amounts of time when grouping many isolates. Some isolates which are known as Bridging

*Corresponding author: Bimal S. Amaradasa, Department of Plant Pathology, University of Nebraska-Lincoln, Lincoln, NE 68583, USA, Tel: +1-402-470-7311; E-mail: bamaradasa2@unl.edu

Received February 21, 2015; Accepted April 22, 2015; Published April 26, 2015

Citation: Amaradasa BS, Lakshman D, Amundsen K (2015) AFLP Fingerprinting for Identification of Infra-Species Groups of Rhizoctonia solani and Waitea circinata. J Plant Pathol Microb 6: 262. doi:10.4172/2157-7471.1000262

Copyright: (C) 2015 Amaradasa BS, et al. This is an open-access article distributed under the terms of the Creative Commons Attribution License, which permits unrestricted use, distribution, and reproduction in any medium, provided the original author and source are credited. 
Isolates (BI) can anastomose with more than one AG leading to further confusion [13].

It is also important to note that anastomosis reactions cannot be used to distinguish subgroups within an AG because subgroups anastomose with each other [14].

Although analysis of Internal Transcribed Spacer (ITS) region is a well-tested method for identifying Rhizoctonia species, it can be cost prohibitive for investigating a large number of samples. Some Rhizoctonia isolates are difficult to sequence due to polymorphisms in the ITS region [15-17]. These isolates may require cloning before sequencing, which adds more time and cost to the analysis. ITS sequence polymorphism may make it difficult to group Rhizoctonia isolates to their AG subgroups [18].

PCR based fingerprinting method Amplified Fragment Length Polymorphism (AFLP) is a cost effective alternative for assessing genetic diversity of many organisms. AFLP is a multilocus marker and does not need prior knowledge of sequence information to generate polymorphic markers. Technology advancements have made AFLP technique a relatively cheap, easy, fast and reliable method to generate hundreds of informative genetic markers [19]. No detailed studies have been done to ascertain whether AFLP on Rhizoctonia should be performed at genus level, species level or infra-species level (i.e. at AG and AG subgroup level or $W$. circinata variety). The objective of this study was to determine if AFLP is capable of revealing AG, AG subgroup or variety of unknown $R$. solani and $W$. circinata isolates commonly occurring on cool-season turfgrasses in comparison to the conventional ITS sequence analysis. Since no detailed analyses have been done to determine whether AFLP is suitable for grouping multiple species of Rhizoctonia together or whether this method is appropriate for deciphering the genetic diversity of isolates within a single Rhizoctonia species, we analyzed $R$. solani and W. circinata isolates together as well as separately.

\section{Materials and Methods}

\section{Isolates used in this study and ITS sequence analysis}

Rhizoctonia isolates $(\mathrm{n}=71)$ used in this study were collected from lawns and golf courses of Virginia and Maryland during summer months of 2007 to 2009 (Table 1). A previous study had identified these isolates to species, AG or AG subgroup level using colony morphology on PDA, anastomosis reactions, and ITS sequence analysis as described by Amaradasa et al. [20]. The present study also included eight tester strains consisting of R. solani (AG 1-IB, 2-2IIIB and 5) and W.circinata (var. zeae and circinata) (Table 2). Accordingly, there were 55 R. solani

\begin{tabular}{|c|c|c|c|c|c|c|}
\hline \multirow{2}{*}{ Isolate } & \multirow{2}{*}{ Origin } & \multirow{2}{*}{ Host } & Management & Species & Anastomosis & GenBank \\
\hline & & & Type & acronym & group & Accession no ${ }^{\ddagger}$ \\
\hline ANP 202B & Annapolis, MD & Tall fescue & Lawn & Rs & AG 2-2IIIB & JX631193 \\
\hline ANP 205A & Annapolis, MD & Tall fescue & Lawn & Rs & AG 2-2IIIB & JX631194 \\
\hline ANP 205B2 & Annapolis, MD & Tall fescue & Lawn & Rs & AG 2-2IIIB & JX631195 \\
\hline ANP 309A & Annapolis, MD & Tall fescue & Lawn & Rs & AG 2-2IIIB & JX631196 \\
\hline ANP 301B & Annapolis, MD & Tall fescue & Lawn & Rs & AG 1-IB & JX631170 \\
\hline ANP 306B & Annapolis, MD & Tall fescue & Lawn & Rs & AG 1-IB & JX631171 \\
\hline ANP 109B & Annapolis, MD & Tall fescue & Lawn & UWC & WAG & JX631224 \\
\hline ANP 304 & Annapolis, MD & Tall fescue & Lawn & UWC & WAG & JX631225 \\
\hline BELT 114 & Beltsville, MD & Tall fescue & Lawn & Rs & AG 2-2IIIB & JX631189 \\
\hline BELT 150 & Beltsville, MD & Tall fescue & Lawn & Rs & AG 2-2IIIB & JX631190 \\
\hline BELT 262 & Beltsville, MD & Tall fescue & Lawn & Rs & AG 2-2IIIB & JX631191 \\
\hline BELT 267 & Beltsville, MD & Tall fescue & Lawn & Rs & AG 2-2IIIB & \\
\hline BELT 26 & Beltsville, MD & Tall fescue & Lawn & Rs & AG 1-IB & JX631156 \\
\hline BELT 2 & Beltsville, MD & Tall fescue & Lawn & Rs & AG 1-IB & JX631157 \\
\hline BELT 5 & Beltsville, MD & Tall fescue & Lawn & Wcz & WAG-Z & JX631239 \\
\hline BELT 159 & Beltsville, MD & Tall fescue & Lawn & Wcz & WAG-Z & JX631237 \\
\hline BELT 228 & Beltsville, MD & Tall fescue & Lawn & UWC & WAG & JX631221 \\
\hline BLBG 6 & Blacksburg, VA & CBG/ABG & Golf green & Rs & AG 2-2IIIB & JX631186 \\
\hline BLBG 13 & Blacksburg, VA & CBG/ABG & Golf green & Rs & AG 2-2IIIB & JX631185 \\
\hline BLBG 20C & Blacksburg, VA & CBG/ABG & Golf green & Rs & AG 2-2IIIB & JX631180 \\
\hline BLBG 22C & Blacksburg, VA & CBG/ABG & Golf green & Rs & AG 2-2IIIB & JX631181 \\
\hline BLBG 32C & Blacksburg, VA & CBG/ABG & Golf green & Rs & AG 2-2IIIB & JX631182 \\
\hline BLBG 320 & Blacksburg, VA & Tall fescue & Lawn & Rs & AG 1-IB & JX631162 \\
\hline BLBG 510 & Blacksburg, VA & Tall fescue & Lawn & Rs & AG 1-IB & JX631165 \\
\hline BLBG 430 & Blacksburg, VA & Tall fescue & Lawn & Rs & AG 1-IB & JX631164 \\
\hline BLBG 350 & Blacksburg, VA & Tall fescue & Lawn & Rs & AG 1-IB & JX631163 \\
\hline BLBG 211 & Blacksburg, VA & CBG/ABG & Golf green & Wcc & WAG & JX631228 \\
\hline BLBG 216 & Blacksburg, VA & CBG/ABG & Golf green & Wcc & WAG & JX631229 \\
\hline BLBG 202 & Blacksburg, VA & CBG/ABG & Golf green & Wcc & WAG & JX631230 \\
\hline BLBG 8 & Blacksburg, VA & CBG/ABG & Golf green & Wcc & WAG & JX631227 \\
\hline HDN 102 & Herndon, VA & CBG/ABG & Golf green & Rs & AG 2-2IIIB & JX631201 \\
\hline HDN 208By & Herndon, VA & Tall fescue & Golf rough & Rs & AG 2-2IIIB & JX631202 \\
\hline
\end{tabular}


Citation: Amaradasa BS, Lakshman D, Amundsen K (2015) AFLP Fingerprinting for Identification of Infra-Species Groups of Rhizoctonia solani and Waitea circinata. J Plant Pathol Microb 6: 262. doi:10.4172/2157-7471.1000262

Page 3 of 10

\begin{tabular}{|c|c|c|c|c|c|c|}
\hline HDN 225 & Herndon, VA & Tall fescue & Golf rough & Rs & AG 2-2IIIB & JX631203 \\
\hline HDN 111A & Herndon, VA & Tall fescue & Golf rough & Rs & AG 1-IB & JX631166 \\
\hline HDN 122A & Herndon, VA & Tall fescue & Golf rough & Rs & AG 1-IB & JX631167 \\
\hline HDN 302 & Herndon, VA & Tall fescue & Golf rough & Rs & AG 1-IB & JX631168 \\
\hline HDN 115A & Herndon, VA & Tall fescue & Golf rough & Wcz & WAG-Z & JX631235 \\
\hline HDN 211 & Herndon, VA & Tall fescue & Golf rough & Wcz & WAG-Z & JX631236 \\
\hline HDN 222A & Herndon, VA & Tall fescue & Golf rough & UWC & WAG & JX631226 \\
\hline LB 312 & Leesburg, VA & Tall fescue & Lawn & Rs & AG 2-2IIIB & JX631192 \\
\hline LB 317 & Leesburg, VA & Tall fescue & Lawn & Rs & AG 2-2IIIB & JX631183 \\
\hline LB 325 & Leesburg, VA & Tall fescue & Lawn & Rs & AG 2-2IIIB & JX631184 \\
\hline LB 4114 & Leesburg, VA & Tall fescue & Golf rough & Rs & AG 2-2IIIB & - \\
\hline LB 4118B & Leesburg, VA & Tall fescue & Golf rough & Rs & AG 2-2IIIB & JX631197 \\
\hline LB 4303 & Leesburg, VA & Tall fescue & Golf rough & Rs & AG 2-2IIIB & JX631198 \\
\hline LB 4316 & Leesburg, VA & CBG/ABG & Golf green & Rs & AG 2-2IIIB & JX631199 \\
\hline LB 4319 & Leesburg, VA & Tall fescue & Golf rough & Rs & AG 2-2IIIB & JX631200 \\
\hline LB 123 & Leesburg, VA & Tall fescue & Lawn & Rs & AG 1-IB & JX631158 \\
\hline LB 124 & Leesburg, VA & Tall fescue & Lawn & Rs & AG 1-IB & JX631159 \\
\hline LB 127 & Leesburg, VA & Tall fescue & Lawn & Rs & AG 1-IB & JX631160 \\
\hline LB 234 & Leesburg, VA & Tall fescue & Lawn & Rs & AG 1-IB & JX631161 \\
\hline LB 4217 & Leesburg, VA & Tall fescue & Golf rough & Rs & AG 1-IB & JX631169 \\
\hline LB 204 & Leesburg, VA & Tall fescue & Lawn & Rs & AG 5 & JX631204 \\
\hline LB 319 & Leesburg, VA & Tall fescue & Lawn & Wcz & WAG-Z & JX631233 \\
\hline LB 228 & Leesburg, VA & Tall fescue & Lawn & Wcz & WAG-Z & JX631234 \\
\hline LB 4116 & Leesburg, VA & Tall fescue & Golf rough & Wcz & WAG-Z & JX631238 \\
\hline BSF 69 & Richmond, VA & Tall fescue & Lawn & Rs & AG 2-2IIIB & JX631176 \\
\hline BSF 50 & Richmond, VA & Tall fescue & Lawn & Rs & AG 2-2IIIB & JX631175 \\
\hline BSF 42 & Richmond, VA & Tall fescue & Lawn & Rs & AG 2-2IIIB & JX631174 \\
\hline BSF 90 & Richmond, VA & Tall fescue & Lawn & Rs & AG 2-2IIIB & JX631177 \\
\hline BSF 207 & Richmond, VA & Tall fescue & Lawn & Rs & AG 2-2IIIB & JX631178 \\
\hline BSF 209 & Richmond, VA & Tall fescue & Lawn & Rs & AG 2-2IIIB & JX631179 \\
\hline BSF 214 & Richmond, VA & Tall fescue & Lawn & Rs & AG 2-2IIIB & JX631188 \\
\hline BSF 127 & Richmond, VA & Tall fescue & Lawn & Rs & AG 2-2IIIB & JX631187 \\
\hline BSF 13 & Richmond, VA & Tall fescue & Lawn & UWC & WAG & JX631223 \\
\hline PW 326 & Woodbridge, VA & Tall fescue & Lawn & Rs & AG 1-IB & JX631173 \\
\hline PW 353 & Woodbridge, VA & Tall fescue & Lawn & Rs & AG 1-IB & JX631172 \\
\hline PW 220 & Woodbridge, VA & Tall fescue & Lawn & Wcz & WAG-Z & JX631232 \\
\hline PW 119 & Woodbridge, VA & Tall fescue & Lawn & Wcz & WAG-Z & JX631231 \\
\hline VABCH 8 & Virginia Beach, VA & Tall fescue & Lawn & Wcz & WAG-Z & - \\
\hline VABCH 10 & Virginia Beach, VA & Tall fescue & Lawn & Wcz & WAG-Z & - \\
\hline
\end{tabular}

*ABG: Annual Bluegrass; CBG: Creeping Bentgrass; Rs: R. solani; Wcz: W. circinata var. zeae; Wcc: W. circinata var. circinata; UWC: Unidentified W. circinata species. ¥ITS sequence.

Table 1: Geographic origin, host, management type, species, and anastomosis group of isolates used in this study*.

\begin{tabular}{|c|c|c|c|c|c|}
\hline Isolate & Species Acronym* & AG & Host $^{\ddagger}$ & Location & Donor ${ }^{\dagger}$ \\
\hline EDHGED 2-1 & Wcc & Not assigned & $A B G$ & California, USA & FW \\
\hline BSCCST 17-1-1 & Wcc & Not assigned & ABG & California, USA & FW \\
\hline AVGCAV & Wcz & WAG-Z & ABG & California, USA & FW \\
\hline M008 & Wcz & WAG-Z & Rice & Japan & MC \\
\hline $\mathrm{Rh102/ \textrm {T }}$ & Rs & AG 5 & Unknown & Unknown & LB \\
\hline $\mathrm{Rh} 63 / \mathrm{T}$ & Rs & AG 5 & wheat crown & California, USA & LB \\
\hline Rh146 & Rs & AG 2-2IIIB & Bentgrass & Georgia, USA & LB \\
\hline BM2 & Rs & AG 1-IB & Unknown & Unknown & BM \\
\hline
\end{tabular}

${ }^{*}$ Rs: $R$. solani; Wcc: W. circinata var. circinata; Wcz: W. circinata var. zeae

${ }^{\ddagger}$ ABG: Annual Bluegrass

tFW: Frank Wong, University of California Riverside, USA (currently Bayer Crop Science, USA). LB: Lee Burpee, University of Georgia, USA. MC: Marc Cubeta, North

Carolina State University, USA.

Table 2: Rhizoctonia and Waitea tester isolates used in this study. 
isolates including tester strains, which consisted of 33 AG 2-2IIIB, 19 AG 1-IB, and three AG 5. A total of 24 isolates represented W.circinata with 13 , six and five isolates belonging to W.circinata var. zeae (Wcz), var. circinata (Wcc) and an unknown W.circinata group (UWC), respectively. In addition to these isolates, ITS phylogram included Genbank deposited ITS sequences of W.circinata varieties agrostis and prodigus.

\section{Generation of AFLP markers}

DNA was purified using the QIAGEN DNeasy plant mini kit (QIAGEN Inc., Valencia, CA) according to the manufacturer's instructions. AFLP analysis explained below was based on the method described by Ceresini et al. [21] and Vos et al. [22]. All reaction plates contained the isolate BELT 267 in duplicate to ascertain reproducibility of AFLP fragments. DNA samples were digested with restriction enzymes EcoRI (New England BioLabs, Beverly, MA) and MseI (New England BioLabs). Thereafter, digested products were ligated with EcoRI Double Stranded (ds) adapter (EA1: 5'-CTCGTAGACTGCGTACC-3' and EA2 $3^{\prime}$-CATCTGACGCATGGTTAA-5') and MseI ds adapter (MA1: 5'-GACGATGAGTCCTGAG-3' and MA2: $3^{\prime}$-TACTCAGGACTCAT-5-3'). Both digestion and ligation reactions were done in one step by preparing a reaction mixture of $20 \mu \mathrm{l}$ having $2 \mathrm{U}$ of each restriction enzyme, $1.2 \mathrm{U}$ of T4 DNA ligase (New England BioLabs), $0.1 \mu \mathrm{M}$ of EcoRI adapter, $1 \mu \mathrm{M}$ of $\mathrm{Mse}$ I adapter and $100 \mathrm{ng}$ of DNA template. The reaction mixture also included $1 \times E c o$ RI buffer $(50 \mathrm{mM} \mathrm{NaCl}, 100 \mathrm{mM}$ Tris- $\mathrm{HCl}, 10 \mathrm{mM} \mathrm{MgCl}, 0.025 \%$ Triton $\mathrm{X}-100), 1 \times$ MseI buffer $\left(50 \mathrm{mM} \mathrm{NaCl}, 10 \mathrm{mM}\right.$ Tris- $\mathrm{HCl}, 10 \mathrm{mM} \mathrm{MgCl}_{2}$ , $1 \mathrm{mM}$ DTT), $1 \times$ T4 ligase buffer $(50 \mathrm{mM}$ Tris- $\mathrm{HCl}, 10 \mathrm{mM} \mathrm{MgCl}$ , $10 \mathrm{mM}$ DTT, $1 \mathrm{mM} \mathrm{ATP}$ ), and $2 \mu \mathrm{g}$ of bovine serum albumin. The reaction mixture was incubated overnight at room temperature to complete digestion and ligation reactions and thereafter, diluted tenfold by adding sterile TE (Tris-EDTA) buffer and stored at $-20^{\circ} \mathrm{C}$ for later use. The first amplification (pre-amplification) was carried out with one selective nucleotide for each primer: EcoRI primer $+A$ (5'-GACTGCGTACCAATTCA-3') and MseI primer $+C$ (5'-GATGAGTCCTGAGTAAC-3'). Each sample of $25 \mu$ included $5 \mu \mathrm{l}$ of digestion and ligation reaction from the previous step, $0.5 \mu \mathrm{M}$ each of EcoRI and MseI primers, $1 \times$ Taq polymerase reaction buffer $(10$ $\mathrm{mM}$ Tris- $\left.\mathrm{HCl}, 50 \mathrm{mM} \mathrm{KCl}, 1.5 \mathrm{mM} \mathrm{MgCl}_{2}\right), 0.2 \mathrm{mM}$ dNTP and $1 \mathrm{U}$ of Taq polymerase (New England BioLabs). The PCR was performed in a thermocycler (MJ Research PTC-200, Global Medical Instrumentation, Ramsey, MN) with initial denaturation at $94^{\circ} \mathrm{C}$ for 2 min followed by 20 cycles of $30 \mathrm{~s}$ at $94^{\circ} \mathrm{C}, 1 \mathrm{~min}$ at $56^{\circ} \mathrm{C}$ and $1 \mathrm{~min}$ at $72^{\circ} \mathrm{C}$. PCR products were diluted ten-fold with TE buffer and used as the template DNA for selective amplification using four EcoRI and MseI primer pairs with three selective nucleotides (EcoRI primer $+A C A$ and $M s e$ I primer $+C A A$, EcoRI primer $+A A A$ and $M s e \mathrm{I}$ primer $+C T A, E c o$ RI primer $+A A C$ and MseI primer $+C A C, E c o$ RI primer $+A G T$ and Mse I primer $+C T G)$. EcoRI and MseI primers were synthesized by Eurofins MWG Operon (Huntsville, AL) and IDT (Coralville, IA), respectively. All EcoRI primers were end labeled with fluorescence dye 6-FAM ${ }^{\mathrm{sm}}$ at the $5^{\prime}$ end. Each selective PCR mixture of $20 \mu \mathrm{l}$ included $4 \mu \mathrm{l}$ of diluted preselective reaction, $0.5 \mu \mathrm{M}$ each of EcoRI and MseI primers, $1 \times$ standard Taq polymerase reaction buffer, $0.2 \mathrm{mM}$ dNTP and $1 \mathrm{U}$ of Taq polymerase. The PCR reaction was performed for 36 cycles with the following cycle profile. Cycle 1 with $30 \mathrm{~s}$ DNA denaturation step at $94^{\circ} \mathrm{C}, 30 \mathrm{~s}$ annealing step at $65^{\circ} \mathrm{C}$, and $1 \mathrm{~min}$ extension step at $72^{\circ} \mathrm{C}$. The same conditions were used in cycle $2-12$ as in cycle 1 , but included a progressive drop in the annealing temperature of $0.7^{\circ} \mathrm{C}$ in each cycle. Cycles $13-36$ included $30 \mathrm{~s}$ at $94^{\circ} \mathrm{C}, 30 \mathrm{~s}$ at $56^{\circ} \mathrm{C}$ and $1 \mathrm{~min}$ at $72^{\circ} \mathrm{C}$. A final extension of $5 \mathrm{~min}$ at $72^{\circ} \mathrm{C}$ completed the reaction. Presence of AFLP banding profiles were confirmed by electrophoresing $5 \mu$ of PCR samples in $1.7 \%$ agarose gel for one hour at $100 \mathrm{~V}$ and visualizing ethidium bromide stained gels under UV light.

\section{AFLP data capture and analysis}

We used the size standard GeneScan ${ }^{\mathrm{ma}} 500 \mathrm{LIZ}^{\circ}$ (Applied Biosystems, Foster City, CA) with capillary electrophoresis system ABI 3730 (Applied Biosystems) to capture AFLP fragments. The size standard was added to each PCR sample for automated data analysis and is essential for precise DNA fragment size comparisons between electrophoresis runs. GeneScan 500LIZ has a DNA fragment sizing range of 35-500 bp with 16 single-stranded labeled DNA fragments. Samples amplified with primers were analyzed by loading a denatured cocktail containing $0.5 \mu \mathrm{l}$ of PCR sample, $9 \mu \mathrm{l} \mathrm{Hi-Di} \mathrm{formamide} \mathrm{(Applied} \mathrm{Biosystems,}$ Warrington) and $0.5 \mu \mathrm{l}$ of 500LIZ. The GeneMapper software V4.1 (Applied Biosystems) was used to extract and analyze raw data files obtained from the ABI 3730. AFLP products and size standard fragments can be distinguished since FAM dye-labeled AFLP products are associated with blue signals/peaks while LIZ dye-labeled size fragments generate orange signals. 500LIZ electropherograms had clear, tall peaks without any missing or extra ones and GeneMapper software correctly detected them. The Analysis Range settings of the software were changed 50 through 500 to limit the allele calling analysis within that range. Thereafter, samples were analyzed using the Advanced peak detector algorithm. DNA fragments smaller than $50 \mathrm{bp}$ were not scored to avoid artefacts of primer-dimer formation. The Advanced mode uses the defined size standard values to select peaks of the size standard on an electropherogram. This is achieved by ratio matching where the software uses relative distances between neighboring peaks to correctly define sizes. A Size Standard Curve is generated for each sample and this is used as a reference to accurately compare and capture the size of AFLP amplicons among sample runs. AFLP amplicons of R. solani and $W$. circinata isolates were analyzed separately as well as together to determine the suitability of this method in each situation. Initially, we created a bin set by setting the minimum peak intensity to 100 relative fluorescent units $(\mathrm{rfu})$ for peaks generated by FAM labeled AFLP products. A bin set is a set of allele definitions specific to a set of samples with a set of analysis conditions. GeneMapper software is capable of scoring alleles directly from a new set of samples without any bin set or using a previously generated bin set. Better results were obtained by first generating a bin set using a low peak amplitude threshold (ex. 100 $\mathrm{rfu}$ ) which captures most of the AFLP fragments and then applying that bin set to analyze the same sample set with higher Peak Amplitude Threshold settings in order to filter weak signals and background noise. Once peaks were scored, a binary table was generated of ones and zeros relating to presence absence of alleles. We tested binary tables generated with peak capture thresholds of 500,1000,1500, and $2500 \mathrm{rfu}$. Each scoring table of zeros and ones generated by four AFLP primers was imported to NTSYS version 2.2 [23] and converted to a different similarity indices using Qualitative data tab of Dis/similarity module. The compared indices included Dice, SM, Phi, O, and Y [2427]. These similarity values were used in MEGA 5 [28] software to construct an UPGMA [25] tree in order to cluster isolates according to their genetic distances. Cophenetic goodness-of-fit tests were also performed as described in NTSYS to ascertain how well the distance matrices are represented by UPGMA dendrograms. For this, COPH module was used to produce a cophenetic value matrix [29] for each UPGMA dendrogram and compared to the relevant distance matrix using the MXCOMP program to compute the correlation between the two matrices. Cophenetic correlation of $>0.9$ is a very good fit while 0.8 to 0.9 is a good fit [23]. The genetic distances generated by different 
similarity indices were used to compute eigenvalues and eigenvectors in NTSYS using Eigen function in the Ordination module. NTSYS was then used to perform Principal Component Analysis (PCA) [30] by plotting the first three eigenvectors for each similarity index tested.

Genetic variability among subpopulations of $R$. solani and $W$. circinata as shown by UPGMA analysis was determined by analysis of molecular variance (AMOVA) [31] in GenAlEx version 6.5 [32]. Since AFLP markers generate a binary matrix without any information of intra-individual variation (heterozygosity), AMOVA was performed by calculating PhiPT $\left(\Phi_{\mathrm{PT}}\right)$ which is an analogue of Wright's $F_{\mathrm{ST}}$. Normally, $F_{\mathrm{ST}}$ and its analogues are greater than zero but rarely exceed 0.5 . An $\mathrm{F}_{\mathrm{ST}}$ value of 0.05 or less is generally considered as reasonably low and may be interpreted to mean that structuring between subpopulations is weak $[33,34]$.

\section{Results}

All four AFLP selective primers produced a large number of polymorphic alleles for each isolate. For instance, the average number of alleles scored per $R$. solani isolate per selective primer was 64 . The two BELT 267 samples in each plate gave similar fingerprinting patterns indicating high reproducibility of the AFLP technique. Binary tables generated with a peak capture threshold of $1000 \mathrm{rfu}$ gave better results than other rfu values in terms of grouping isolates to their correct AGs. None of the UPGMA dendrograms constructed with different similarity matrices could correctly group all $R$. solani and $W$. circinata isolates when analyzed together (results not shown). A few isolates of AG 2-2IIIB grouped with W. circinata var. zeae (Wcz) group while $W$. circinata var. circinata (Wcc) cluster consisted of a few Wcz isolates. Therefore, we did not proceed with the analysis of combined AFLP data for $R$. solani and $W$. circinata isolates.

\section{AFLP analysis of Rhizoctonia solani isolates}

The AFLP primer pairs EcoRI-AAC and MseI-CAC, EcoRI-AGT and MseI-CTG, EcoRI-AAA and MseI-CTA, and EcoRI-ACA and MseI$C A A$ produced 230, 234, 265, and 213 alleles, respectively for the isolates analyzed. Allele 7 produced by EcoRI-AAA and MseI-CTA primer pair was monomorphic across all $R$. solani isolates. AG 1-IB isolates had a total of three monomorphic alleles while AG 2-2IIIB resulted in two. There were no clones resembling isolates with same DNA fingerprinting pattern among AG 1-IB or AG 2-2IIIB. All the alleles (942 in total) produced by four primer pairs were pooled together to make a single binary matrix for calculating genetic similarity of isolates. We compared the dendrograms produced by different similarity indices to the results of ITS sequence analysis in a previous study having all but BELT 267 and LB 4114 isolates (Supplemental Figure 1) [20]. Though all the similarity indices tested largely grouped R. solani isolates to their correct AG, the Dice coefficient based UPGMA tree generated the highest cophenetic correlation value of 0.8968 (Figure 1 ) and corresponded very well with ITS analysis (Supplemental Figure 1). The tree consisted of three clusters that represented the correct AG or AG subgroup (i.e. AG 1-IB, AG 2-2IIIB or AG 5) of each $R$. solani isolate studied (Figure 1). The PCA for R. solani isolates clearly separated them into AG or AG subgroup along dimension 2 (Figure 2). This difference was tested using AMOVA, which showed significant difference among AG subgroups ( $p=0.0001$ ) representing $14.2 \%$ of the total genetic variance (Table 3 ).

\section{AFLP analysis of Waitea circinata isolates}

The same selective primers mentioned above viz., EcoRI-AAC and MseI-CAC, EcoRI-AGT and MseI-CTG, EcoRI-AAA and MseI-
CTA, and EcoRI-ACA and MseI-CAA produced, 97, 122, 91, and 175 alleles, respectively for the 24 Waitea isolates. All alleles were polymorphic across the Waitea isolates. However, there were one, five and 20 monomorphic alleles among Wzc, Wcc, and UWC isolates, respectively. Similar to $R$. solani, there were no clonal isolates among $W$. circinata isolates. Binary tables generated for each primer set were pooled to produce a single table of 485 alleles and used to calculate genetic similarity values. The $\mathrm{Y}$ coefficient gave the best UPGMA tree with the highest cophenetic correlation value of 0.8 (Figure 3 ). Although UPGMA tree largely corresponded with ITS phylogram (Figure 4), there were few differences. BELT 159 and BELT 5 with colony morphology similar to Wcz on PDA grouped separately in the ITS analysis (Figure 4), whereas AFLP dendrogram had them grouped together with the rest of Wcz isolates (Figure 3). Though the five UWC isolates formed a single large cluster in both ITS phylogram and AFLP

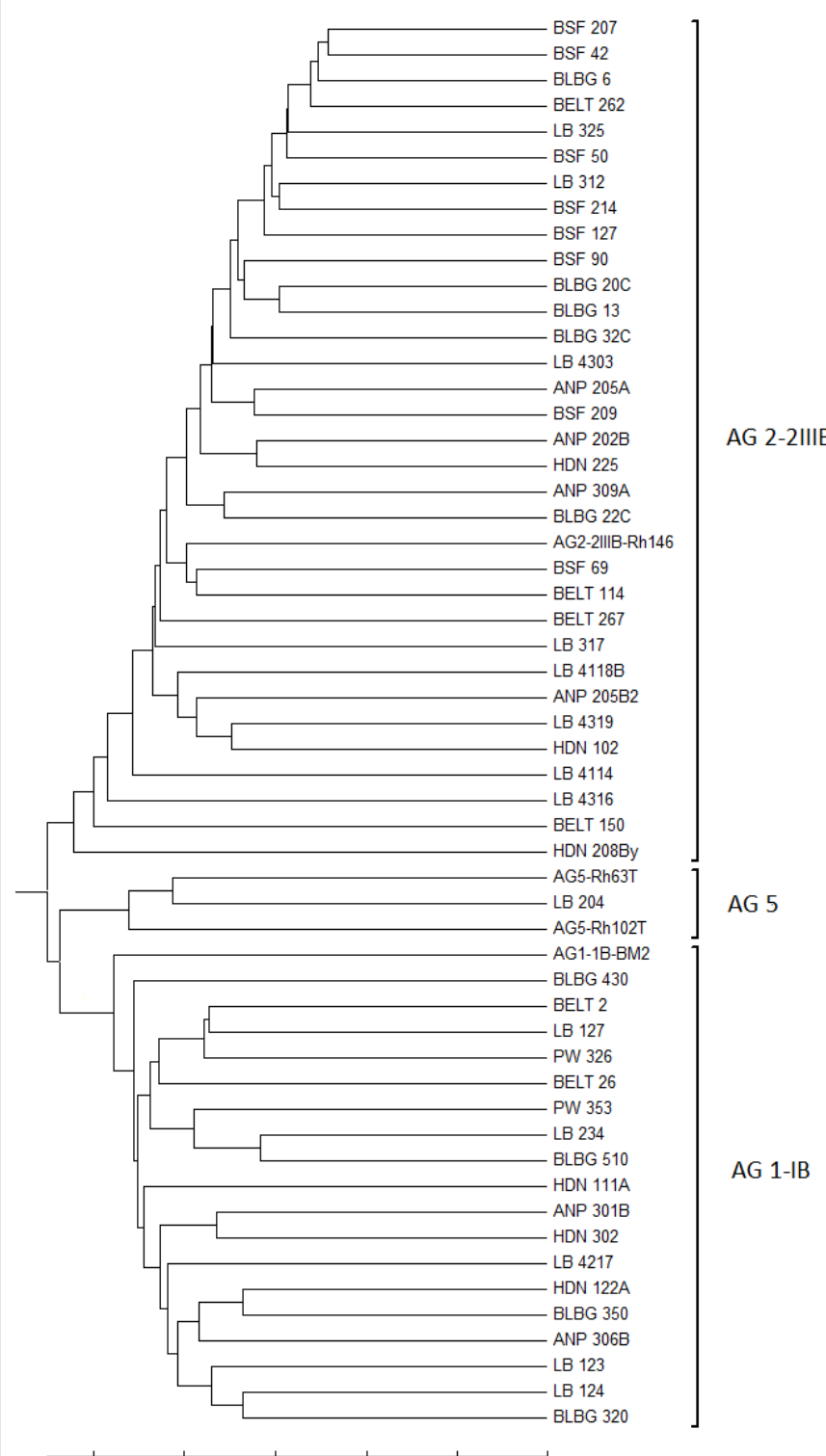

Figure 1: UPGMA dendrogram for $R$. solani isolates derived from Dice's genetic distance matrix. Isolates of $R$. solani anastomosis groups AG 1-IB, 2-2IIIB, and 5 grouped separately and are indicated in the tree. 


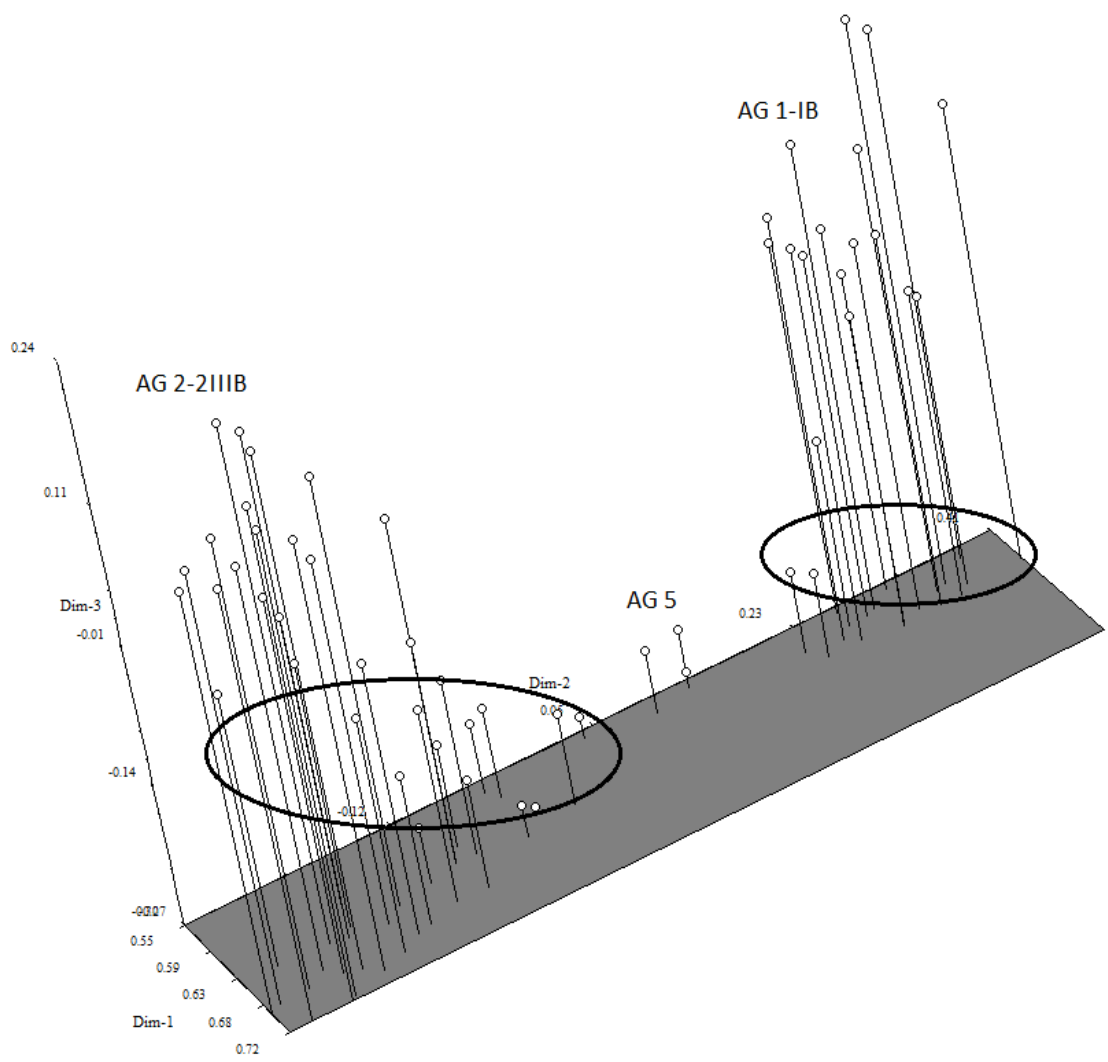

Figure 2: Placement of $R$. solani isolates on a three dimensional plot using PCA based on Dice's genetic distance matrix.

\begin{tabular}{|c|c|c|c|c|c|c|}
\hline Group & Source of variation & df & SS & $\%$ Variation & $\Phi_{\mathrm{PT}}$ & $P$ value \\
\hline \multirow[t]{3}{*}{ R. solania } & Among populations & 2 & 982 & 14 & 0.142 & 0.001 \\
\hline & Within populations & 52 & 7605 & 86 & 0.858 & 0.001 \\
\hline & Total & 54 & 8587 & & & \\
\hline \multirow[t]{3}{*}{ W. circinata ${ }^{b}$} & Among populations & 2 & 348 & 12 & 0.120 & 0.0001 \\
\hline & Within populations & 21 & 1840 & 86 & 0.880 & 0.0001 \\
\hline & Total & 23 & 2188 & & & \\
\hline
\end{tabular}

$P$ value for randomization test for $\Phi P T$ is based on 999 permutations across the full data set.

$R$. solani group consisted of three subpopulations namely, AG 1-IB, AG 2-2IIIB, and AG 5.

$W$. circinata group consisted of varieties zeae, circinata and an unidentified subgroup.

Table 3: Analysis of molecular variance (AMOVA) of $R$. solani and $W$. circinata isolates based on four AFLP primer data.

dendrogram, they resolved differently thereafter. UWC isolate BSF 13 grouped close to W. circinata var. prodigus in the ITS tree (GenBank accessions HM597147, HM597146, and HQ850254), while UWC isolate ANP 109B grouped with W. circinata var. agrostis (AB213578 and $\mathrm{AB13572}$ ) (Figure 4). The rest of the UWC isolates (ANP 304, BELT 228, and HDN222A) grouped in between (Figure 4). The AFLP dendrogram (Figure 3 ) agreed with the ITS tree clearly by grouping BSF 13 and ANP 109B in two sub-clusters but ANP 304 and BELT 228 did not cluster closely as in ITS phylogram. We did not have AFLP data of varieties agrostis, prodigus and other GenBank accessions used in the Figure 4 for comparison. Wcc isolates clustered similarly in both AFLP and ITS trees. PCA clearly separated $W$. circinata isolates to their subgroups Wzc, Wcc and UWC along dimension 2 and 3 (Figure 5), which was corroborated with an AMOVA that showed significant difference among $W$. circinata subgroups $(p=0.0001)$, representing $12.0 \%$ of the total genetic variance (Table 3 ).

\section{Discussion}

The present study investigated the applicability of the AFLP technique for grouping $R$. solani and $W$. circinata isolates into their infra-species level. In this method, genomic DNA is digested with two restriction endonucleases and two double stranded oligonucleotide adapters are ligated to each fragment. These modified fragments are amplified by two primers recognizing the adapter sequences and adjacent restriction site/s using PCR [22,35]. The resulting banding patterns are highly reproducible and the proportion of the genome analyzed is larger than other DNA fingerprinting techniques such as RAPD [36]. When both $W$. circinata and $R$. solani isolates were analyzed together, AFLP markers did not result in an acceptable dendrogram. It is possible that co-migration of AFLP amplicons generated by genetically distant Rhizoctonia and Waitea isolates have caused this. High variability of AFLP fingerprinting profiles among distant taxa reduces similarities among them to level of chance [19]. 


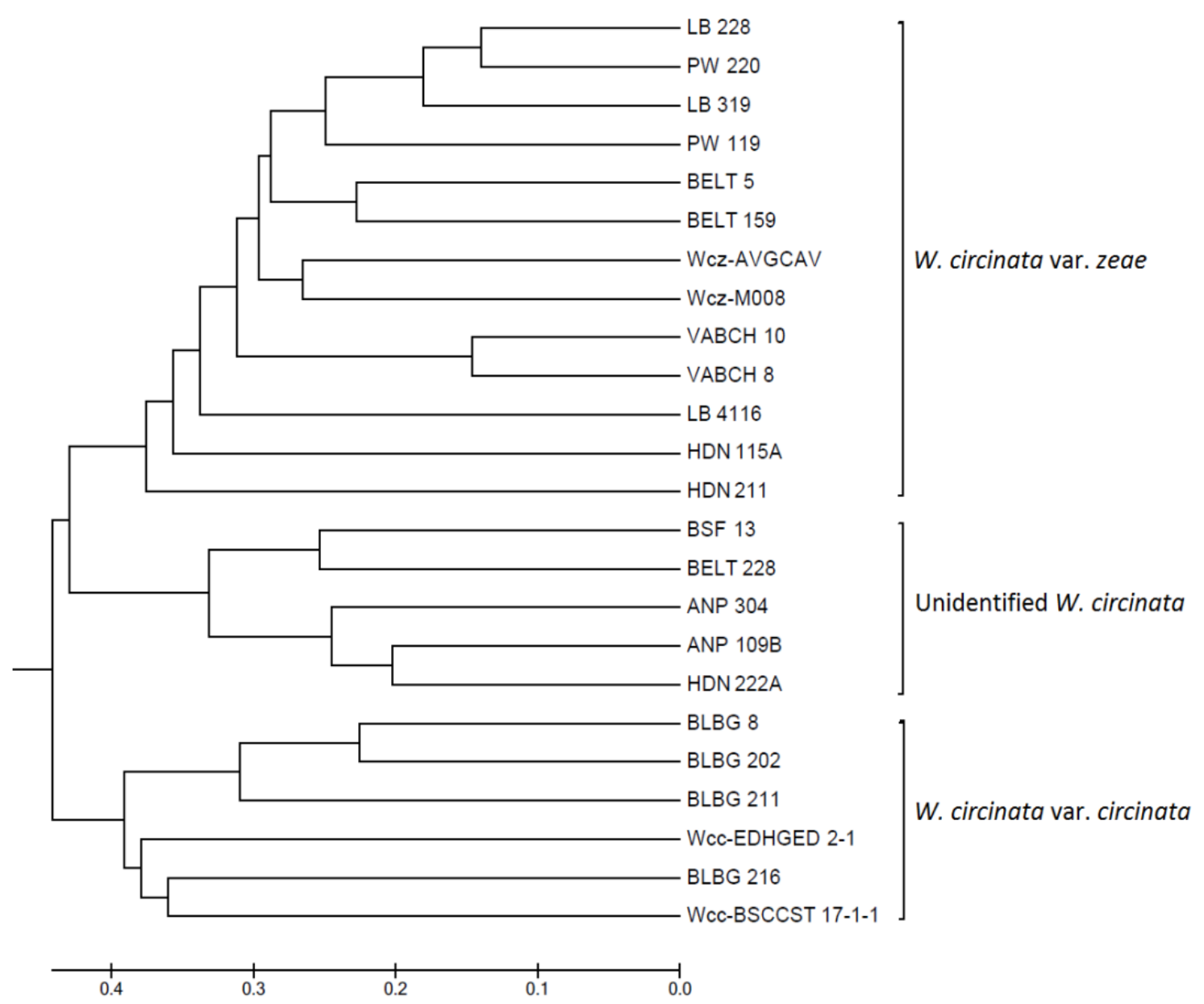

Figure 3: Dendrogram based on UPGMA clustering algorithm for W. circinata isolates derived from Dice's genetic distance matrix. W. circinata variety of each cluster is indicated in the tree.

Therefore, AFLP is not useful to make phylogenetic inferences among higher taxonomic levels but is more suitable for deriving relationships among closely related lineages.

The AFLP markers used in our analysis was able to accurately resolve $R$. solani isolates to AGs and AG subgroups. Clustering of isolates within the UPGMA dendrogram corresponded well with ITS pylogram and was also corroborated by the PCA scree plots. The AMOVA results also showed significant difference between these subgroups. Both PCA and AMOVA results are positive indicators of the confidence of UPGMA clusters.

ITS sequence analysis grouped Wcz isolates BELT 159 and BELT 5 separately from rest of the Wcz cluster. There was high sequence dissimilarity of $8.5 \%$ between above two isolates and other $\mathrm{Wcz}$ (sequences dissimilarity not shown). It is possible that ITS region polymorphism of these two isolates have contributed to the discrepancy. Previous studies have reported the ITS region polymorphism within Rhizoctonia isolates and how it can compromise accuracy of phylograms $[17,18]$. Contrary to the results of ITS sequence clustering, AFLP analysis grouped these two isolates within the Wcz cluster. Since AFLP generates multilocus markers, the effect of polymorphism on a single locus is negligible.

Contrary to our findings, previous reviews indicate AFLP and other DNA fingerprinting techniques are more efficacious for studying genetic variation of Rhizoctonia at the individual level rather than at the subgroup level within an AG or different AGs [6,37]. However, these hypotheses were based on few studies without proper investigation of analyzing a large number of Rhizoctonia and Waitea isolates belonging to different AGs. Ceresini et al. [21] employed the AFLP technique to evaluate genetic diversity of isolates within AG3 obtained from potato (PT) and tobacco (TB). AFLP analysis on $32 \mathrm{PT}$ and $36 \mathrm{~TB}$ isolates placed them into two distinct groups based on their host. A similar genetic diversity study of $R$. solani AG4 isolates obtained from the rhizosphere of six vineyards in Mexico was reported by Meza-Moller et al. [38]. They analysed 41 Rhizoctonia isolates using AFLP markers, which revealed three main groups in the UPGMA dendrogram and six groups from principal component analysis. None of the above studies included different AGs. López-Olmos [39] grouped isolates of AG 2-3, AG BI, and AG 5 from common bean using AFLP. However, each AG was represented by only one or a few isolates, thus limiting applicability of AFLP fingerprinting in deriving AGs of unknown isolates. No peer reviewed documentation is available on performing AFLP on different $W$. circinata varieties. Therefore, we feel our analysis is unique since we used a large number of $R$. solani and $W$. circinata isolates to test applicability of AFLP in resolving isolates to AG and AG subgroup level. 


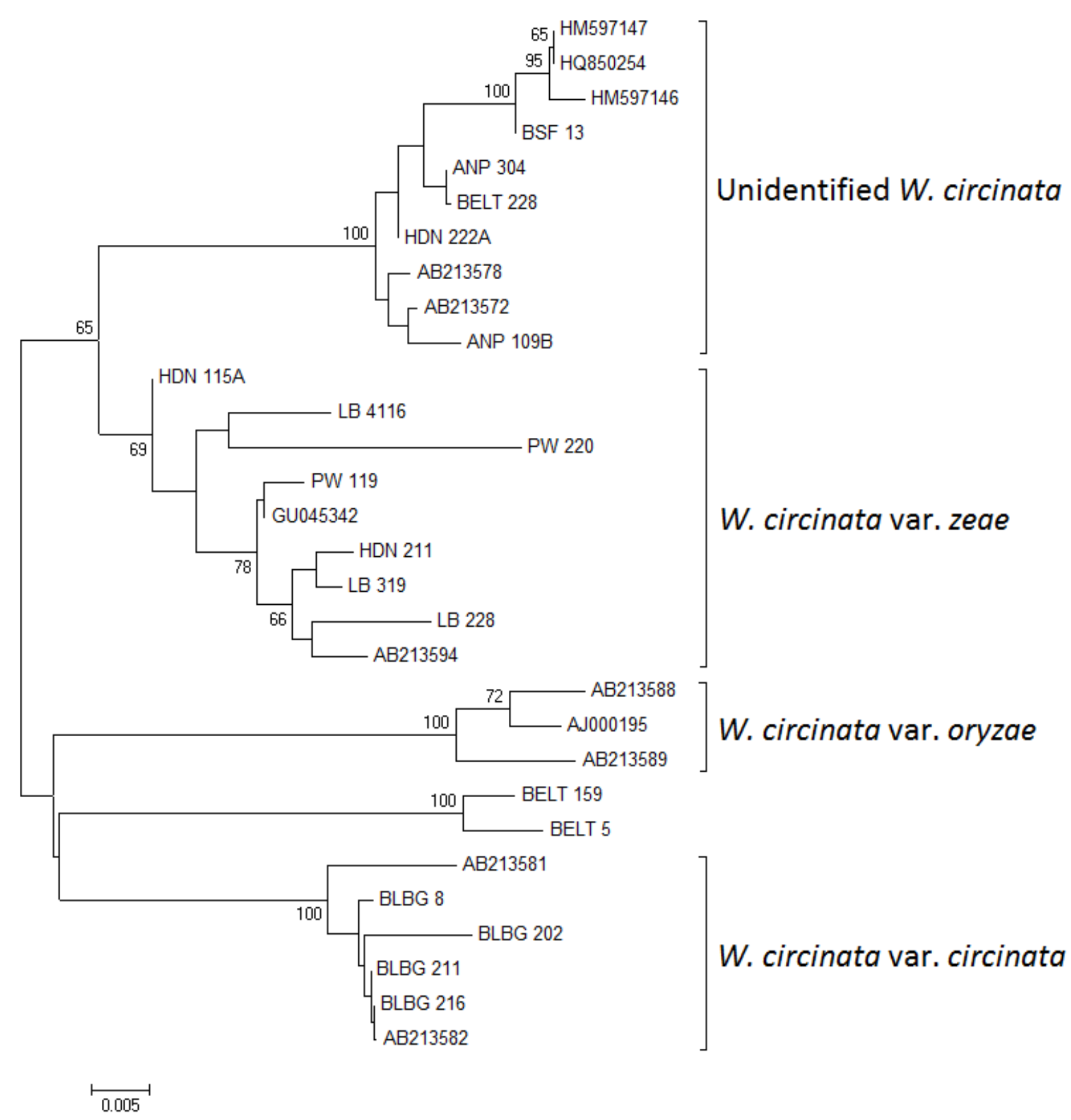

Figure 4: The Neighbour-joining tree of $W$. circinata isolates based on ITS sequence analysis. Bootstrap values $65 \%$ and above assessed by 500 replications are shown next to the branches. The tree is midpoint rooted. The clades of $W$. circinata varieties circinata, oryzae, zeae and unidentified $W$. circinata group (UWC) are indicated on the tree. Taxons starting with $\mathrm{AB}, \mathrm{AJ}, \mathrm{GU}, \mathrm{HM}$, and $\mathrm{HQ}$ are GenBank accessions. UWC isolate BSF 13 grouped closed to W. circinata variety prodigus (accessions HM597147, HQ850254, and HM597146) whereas UWC isolate ANP 109B is closely clustering with variety agrostis (AB213578 and AB213572). GU045342 and AB213594 are W. circinata var. zeae ITS sequences. AB213588, AJ000195 and AB213589 are W. circinata var. oryzae ITS sequences while AB213581 and AB213582 belong to W. circinata var. circinata.

We used the ABI 3730 electrophoresis system to capture AFLP amplicons since it is sensitive enough to differentiate fragments having one base pair difference. This aided in scoring a large number of polymorphic fragments for the four AFLP primers employed (942 and 485 fragments across $R$. solani and W. circinata isolates, respectively). However, size standard used with the ABI 3730 capillary gel electrophoresis system limited the longest fragment size that can be scored to $500 \mathrm{bp}$. Although, scanning gel images can record longer fragments, this method results in less number of total markers compared to capillary gel electrophoresis system and also requires additional labor. When GeneMapper is used it is important to optimize the peak capture amplitude to get the best results. A peak having low amplitude may be generated from background noise and not represent a true AFLP fragment. Therefore, it is necessary to test with different peak detection levels and choose the best for a particular data set. Best peak height depends on run conditions of the capillary electrophoresis system and AFLP samples. Our data set gave better results when the peak capture threshold was set to $1000 \mathrm{rfu}$. GeneMapper is also capable of analyzing multiplexed AFLP fragments. Multiplexing refers to the labeling of amplicons of different isolates with different fluorescent 


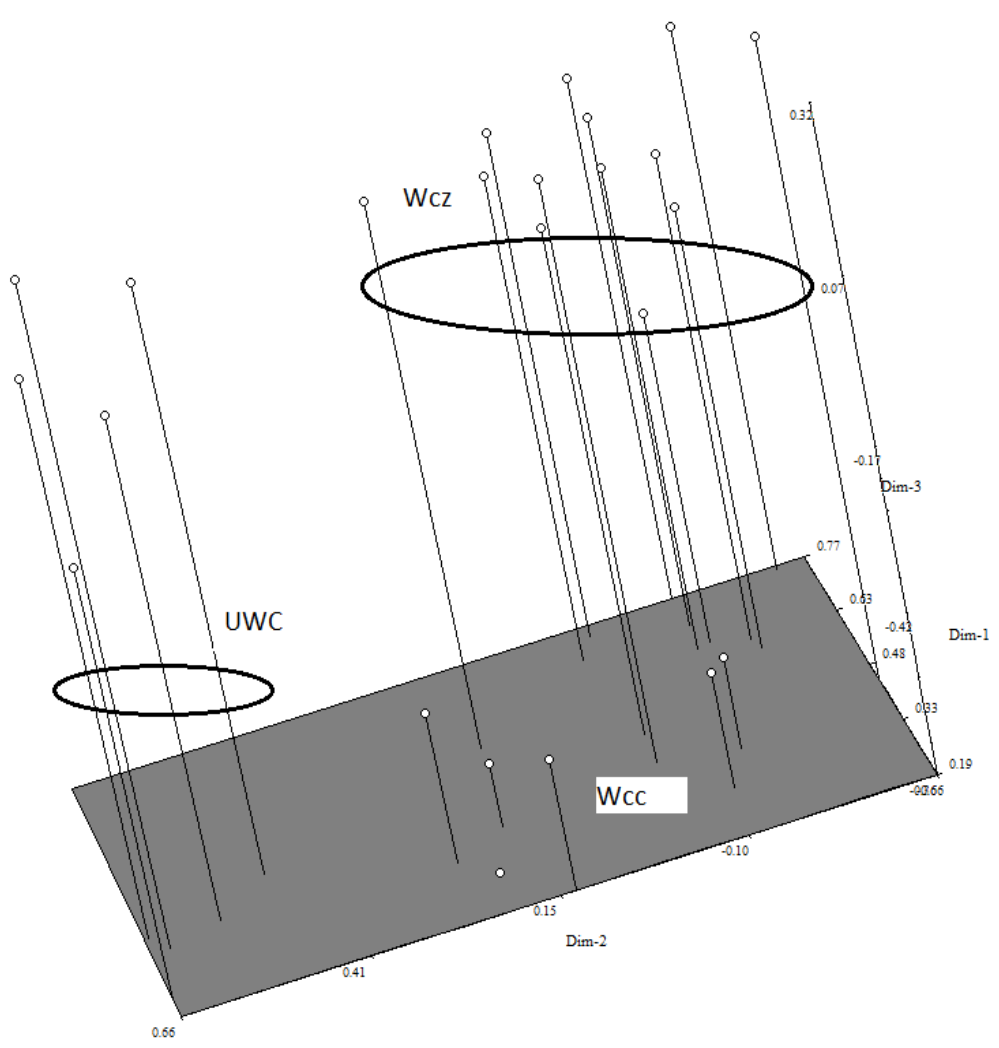

Figure 5: Three dimensional PCA scatter diagram of studied Waitea circinata isolates along first three principal components based on $\mathrm{Y}$ genetic distance matrix.

dyes and analyzing as a single sample. This dramatically reduces the cost of AFLP analysis via capillary electrophoresis.

The main disadvantage of AFLP lies on the dominance nature of its markers which make it unable to determine homologous alleles. Due to this, amid all of the benefits of the AFLP technique such as high reliability, ability to generate molecular markers from uncharacterized organisms, etc., it cannot replace co-dominant makers such as RFLP and microsatellites, completely. Nevertheless, our results showed AFLP can be used successfully to determine genetic structure of unknown $R$. solani and $W$. circinata isolates infecting cool-season turfgrasses by identifying to infra-species level. Rhizoctonia species infecting turfgrasses are difficult to identify using disease symptoms. Accurate identification of causal pathogens to AG or AG subgroup is important since they have differential sensitivity to fungicides and environmental conditions. Our analysis show AFLP is a good alternative for classical methods to characterize a large number of unknown $R$. solani and $W$. circinata isolates to infra-species level reliably and cost effectively.

\section{Acknowledgements}

This research was partially funded by the United States Golf Association.

\section{References}

1. Burpee L, Martin B (1992) Biology of Rhizoctonia species associated with turfgrass. Plant Disease 76: 112-117.

2. De La Cerda KA, Douhan GW, Wong FP (2007) Discovery and characterization of Waitea circinata var. circinata affecting annual bluegrass from the western United States. Plant Disease 91: 791-797.

3. Kammerer SJ, Burpee LL, Harmon PF (2011) Identification of a new Waitea circinata variety causing basal leaf blight of seashore paspalum. Plant Disease 95: 515-522.
4. Toda T, Hayakawa T, Mghalu JM, Yaguchi S, Hyakumachi M (2007) A new Rhizoctonia sp. closely related to Waitea circinata causes a new disease of creeping bentgrass. Journal of General Plant Pathology 73: 379-387.

5. Lübeck M, Poulsen H (2001) UP-PCR cross blot hybridization as a tool for identification of anastomosis groups in the Rhizoctonia solani complex. FEMS Microbiol Lett 201: 83-89.

6. Sharon M, Kuninaga S, Hyakumachi M, Sneh B (2006) The advancing identification and classification of Rhizoctonia spp. using molecular and biotechnological methods compared with the classical anastomosis grouping Mycoscience 47: 299-316.

7. Zhang M, Dernoeden PH (1995) Facilitating anastomosis grouping of Rhizoctonia solani isolates from cool-season turfgrasses. HortScience 30 : 1260-1262.

8. Smiley RW, Dernoeden PH, Clarke BB (2005) Compendium of Turfgrass Diseases. (3rdedn), American Phytopathological Society, St. Paul, MN.

9. Martin SB, Campbell CL, Lucas LT (1984) Response of Rhizoctonia blights of tall fescue to selected fungicides in the greenhouse. Phytopathology 74: 782 785.

10. Martin SB, Lucas LT, Campbell CL (1984) Comparative sensitivity of Rhizoctonia solani and Rhizoctonia-like fungi to selected fungicides in vitro. Phytopathology 74: 778-781.

11. Carling DE, Helm DJ, Leiner RH (1990) In vitro sensitivity of Rhizoctonia solan and other multinucleate and binucleate Rhizoctonia to selected fungicides. Plant Disease 74: 860-863.

12. Kataria HR, Hugelshofer U, Gisi U (1991) Sensitivity of Rhizoctonia species to different fungicides. Plant Pathology 40: 203-211.

13. Ogoshi A (1987) Ecology and pathogenicity of anastomosis and intraspecific groups of Rhizoctonia solani Kühn. Annual Review of Phytopathology, 25: 125142.

14. Carling DE (1996) Grouping in Rhizoctonia solani by hyphal anastomosis reaction. In B Sneh, S Jabaji-Hare, S Neate, G Dijst eds Rhizoctonia species: 
Citation: Amaradasa BS, Lakshman D, Amundsen K (2015) AFLP Fingerprinting for Identification of Infra-Species Groups of Rhizoctonia solani and Waitea circinata. J Plant Pathol Microb 6: 262. doi:10.4172/2157-7471.1000262

Taxonomy, Molecular Biology, Ecology, Pathology and Disease Control. Kluwer Academic Publishers, Dordrecht.

15. Boysen M, Borja M, del Moral C, Salazar O, Rubio V (1996) Identification at strain level of Rhizoctonia solani AG4 isolates by direct sequence of asymmetric PCR products of the ITS regions. Curr Genet 29: 174-181.

16. Strausbaugh CA, Eujayl IA, Panella LW, Hanson LE (2011) Virulence, distribution and diversity of Rhizoctonia solani from sugar beet in Idaho and Oregon. Canadian Journal of Plant Pathology 33: 210-226.

17. Grosch R, Schneider JH, Peth A, Waschke A, Franken P, et al. (2007) Development of a specific PCR assay for the detection of Rhizoctonia solani AG 1-IB using SCAR primers. J Appl Microbiol 102: 806-819.

18. Pannecoucque J, Höfte M (2009) Detection of rDNA ITS polymorphism in Rhizoctonia solani AG 2-1 isolates. Mycologia 101: 26-33.

19. Mueller UG, Wolfenbarger LL (1999) AFLP genotyping and fingerprinting. Trends Ecol Evol 14: 389-394.

20. Amaradasa BS, Horvath BJ, Lakshman DK, Warnke SE (2013) DNA fingerprinting and anastomosis grouping reveal similar genetic diversity in Rhizoctonia species infecting turfgrasses in the transition zone of USA. Mycologia 105: 1190-1201.

21. Ceresini PC, Shew HD, Vilgalys RJ, Cubeta MA (2002) Genetic diversity of Rhizoctonia solani AG-3 from potato and tobacco in North Carolina. Mycologia 94: $437-449$

22. Vos P, Hogers R, Bleeker M, Reijans M, van de Lee T, et al. (1995) AFLP: a new technique for DNA fingerprinting. Nucleic Acids Res 23: 4407-4414.

23. Rohlf FJ (2005) NTSYS-pc: numerical taxonomy and multivariate analysis system. Version 2.2. Setauket, New York: Exeter Software.

24. Dice LR (1945) Measures of the amount of ecologic association between species. Ecology 26: 297-302.

25. Sneath PHA, Sokal RR (1973) Numerical taxonomy. W.H. Freeman and Co. San Francisco, CA

26. Sokal RR, Michener CD (1958) A statistical method for evaluating systematic relationships. University of Kansas Science Bulletin 38: 1409-1438.

27. Sokal RR, Sneath PHA (1963) Principles of numeric taxonomy. W.H. Freeman, San Francisco, pp. 359
28. Tamura K, Peterson D, Peterson N, Stecher G, Nei M, et al. (2011) MEGA5: molecular evolutionary genetics analysis using maximum likelihood evolutionary distance, and maximum parsimony methods. Mol Biol Evol 28 2731-2739.

29. Rohlf FJ, Sokal RR (1981) Comparing numerical taxonomic studies. Systematic Zoology 30: 459-490.

30. Hotelling $\mathrm{H}$ (1933) Analysis of a complex of statistical variables into principa components. Journal of Educational Psychology 24: 417-520.

31. Excoffier L, Smouse PE, Quattro JM (1992) Analysis of molecular variance inferred from metric distances among DNA haplotypes: application to human mitochondrial DNA restriction data. Genetics 131: 479-491.

32. Peakall R, Smouse PE (2012) GenAIEx 6.5: genetic analysis in Excel. Population genetic software for teaching and research--an update. Bioinformatics 28 2537-2539.

33. Wright S (1978) Evolution and the Genetics of Populations. Variability within and among natural populations. Vol 4. The University of Chicago Press Chicago.

34. Balloux F, Lugon-Moulin N (2002) The estimation of population differentiation with microsatellite markers. Mol Ecol 11: 155-165.

35. Lübeck M (2004) Molecular characterization of Rhizoctonia solani. In DK Arora, GG Khachatourians eds Applied mycology and biotechnology Volume 4: Fungal genomics. Elsevier B.V., Amsterdam.

36. Majer D, Mithen R, Lewis BG, Vos P, Oliver RP (1996) The use of AFLP fingerprinting for the detection of genetic variation in fungi. Mycological Research 100: 1107-1111.

37. Cubeta MA, Vilgalys R (1997) Population Biology of the Rhizoctonia solan Complex. Phytopathology 87: 480-484.

38. Meza-Moller A, Esqueda M, Sanchez-Teyer F, Vargas-Rosales G, Gardea AA, et al. (2011) Genetic Variability in Rhizoctonia solani Isolated from Vitis vinifera based on Amplified Fragment Length Polymorphism. American Journa of Agricultural Biology 6: 317-323.

39. López-Olmos K Hernandez-Delgado S, Mayek-Perez N (2005) AFLP fingerprinting for identification of anastomosis groups of Rhizoctonia solan isolates from common bean (Phaseolus vulgaris L.) in Mexico. Revista Mexicana de Fitopatologia 23: 147-151. 